\title{
INDICADORES DE SUSTENTABILIDADE EM SiMUlaÇÕES DE NEGÓCIOS: UMA PROPOSIÇÃO NO CONTEXTO DO JOGO DE EMPRESAS SEE
}

\author{
Rafael Borim de Souza \\ DautorandbemAdministração pdo Progama dePósGraduaçãoemAdministraçãoda \\ UnivesidadeFedkal db Paraná (PPGADMUUPR), MestreemAdministraçãopdo \\ Progama dePósGraduação emAdministraçãoda UnivesidadeEstadual deManingá em \\ Consório coma UniveridadeEstadual deLondina (PPA-UEM/ UEL), Especialista \\ emContrdadonia eFinanģas pda Pontifícia UnivesidadeCatadica do Paraná eemGestão \\ Empresarial pda Escda Brasileira deAdministração Pública edeEmpresas da Fundação \\ Géúlio Varcase Badhard emAdministração pda Pontifía UniversidadeCatdica dbParaná, \\ Pesquisador inscito mo gupo depesquisas Pesscas, Comptênias eSustentabilidadé \\ rafabarim@yahoacom \\ Paulo da Costa Lopes \\ DattradbemEngenharia deProdurão pda UniveridadeFedkal deSanta Cataina, \\ Mestradb emA dinistracẫo pda UniversidadeFedaral dbRio deJaneiro, Graduadb \\ emAdninistracão pda UniversidadeEstadual deLondina, Professor Associadoda Uni- \\ vesidadeEstadual deLondina eProfessor Convidadb da Fundação Gedúlio Varcas- RJ \\ plopes@sercontd.combr
}

RESUMO

O artigo foi desenvolvido com o objetivo de propor a inserção de indicadores de sustentabilidade em simulações de negócios. Para tanto, foi realizada uma pesquisa básica, qualitativa, descritiva, bibliográfica e documental. Foi elaborado um levantamento teórico-metodológico sobre jogos de empresas e sustentabilidade, foi introduzida a Gldbal ReportingInitiative(G RI) como promotora de um padrão de comunicação global em ações empresariais sustentáveis, e apresentou-se o jogo de empresas SEE (Simulador de Estratégia Empresarial). Este artigo, entre outros propósitos, intenciona identificar, pela realidade dos relatórios sustentáveis brasileiros, estruturados segundo as diretrizes da $\mathrm{GRI}$, e publicados em 2008, quais os indicadores - EC1, EN3, HR6, LA1, PR5 e SO 1 - mais reportados por essas empresas. Esses são os indicadores de sustentabilidade propostos para serem inseridos em uma ambiência de simulações de negócios amparada pelo jogo de empresas SEE.

Palavras-chave: Jogos de Empresas. Sustentabilidade. Gldbal ReportingInitiative

\section{ABSTRACT}

\begin{abstract}
This artidehas been deudqpel with themain djeetive of proposing theinsertion of sustaimableindicators in thebusiness simulation enironment. Thus, it has been carried at a basic, qualitative, descriptive, bibliographic and dbametal resench A theorical and mothoblogंcal survey about business simlation and sustaimability has been daborated It has also been introdured theGldbal ReportingInitiative (GRI) as a supporter of standard ddoel commication in sustainable enterpiseads Finally, it has been preented thebusiness camesaftuta reESS (EnterpriseStratey Similator). One of thepurposes of this artideistoidantify through theBrazilian sustainablereports that werestructured in accordanewith theGRI diretives and published in 2008, what werethemost repated indicatorsin theseBrazilian douments, which are EC1, EN3, HR6, LA1, PR5 andSO1. Thesearethesustainableindicators proposed to beinseted in a business similation enironmet suppoted by theESS.
\end{abstract}

Keywords: Business Simulation. Sustainability. Gldbal Reparting Initiative 


\section{IINTRODUÇÃo}

Observa-se a emergência de um novo paradigma pautado por valores de sustentabilidade social e ambiental, interessado em prover as gerações presentes de suas necessidades por meio do uso consciente e responsável dos recursos oferecidos pela natureza, de maneira que, no futuro, as sociedades existentes também possam ter sua sobrevivência assegurada nesse mesmo território. Verifica-se, assim, a necessidade de uma articulação entre os diversos atores sociais, tais como governos, organizações com ou sem fins lucrativos, e diversas comunidades atingidas pelas atividades empresariais.

As organizações, cientes de sua representatividade social, passam a promover práticas gerenciais alinhadas com as premissas de um desenvolvimento sustentável, ao se preocupar com a integridade da vida humana, a dignidade social dos indivíduos e com o bem-estar das comunidades direta e indiretamente afetadas por suas atividades operacionais. E ntre as metodologias abordadas, destaca-se a importância da responsabilidade social empresarial, reconhecida como representante de um modelo de gestão amparado por valores, missões e estratégias organizacionais, aliadas em articular empresas, sociedade e meio ambiente.

Entre as iniciativas que apresentam à sociedade ações empresariais que legitimem a emergência dessas novas premissas sociais encontra-se a publicação de relatórios sustentáveis. Esses documentos reportam ao meio ambiente iniciativas socialmente responsáveis adotadas pelas empresas no intuito de reduzirem os impactos sociais, ambientais e econômicos gerados por suas operações. Nesses relatórios constam inúmeros indicadores de sustentabilidade.

Os seres humanos que vivenciam o cotidiano organizacional são fundamentais para 0 alcance desses indicadores, pois por eles os processos adquirem caráter contínuo e alcançam efetividade pela conquista dos resultados estabelecidos. Logo, uma aprendizagem, aliada a uma interpretação sobre a importância desses movimentos sustentáveis por parte dos stakehddarsenvolvidos nas atividades organizacionais, torna-se imprescindível.

Essa possibilidade alcança um escopo prático por meio de simulações de negócios, uma vez que representam uma ferramenta de desenvolvimento individual e organizacional que potencializa a compreensão e disseminação de conceitos e fenômenos inerentes a um paradigma pautado por valores de sustentabilidade. É nesse contexto que se estabelece 0 presente artigo. Mediante a necessidade de as organizações mostrarem-se ao meio como atores sustentáveis; os stakdndders participantes dos processos cotidianos do ambiente empresarial precisam compreender em plenitude as possíveis ações e decisões tomadas, a fim de que elas confluam diretamente em resultados socialmente responsáveis. Assim, o objetivo deste estudo é propor a inserção de indicadores de sustentabilidade em simulações de negócios.

Um dos propósitos deste artigo é identificar, pela realidade dos relatórios sustentáveis brasileiros publicados em 2008, quais os indicadores mais reportados. Por esse levantamento, aqueles que foram mais frequentes serão apresenta- dos como possíveis indicadores a ser inseridos em uma ambiência de simulação de negócios amparada pelo jogo de empresas SEE (Simulador de Estratégia Empresarial).

O artigo foi estruturado em dez seções: introdução; jogos de empresas como ferramentas de simulação interessantes ao desenvolvimento de uma consciência organizacional sustentável; contextualização da ascensão de um novo paradigma pautado por valores de sustentabilidade social e ambiental; comunicação global de ações sustentáveis: Gldbal ReparingInitiative,jogo de empresas SE E; metodologia e procedimentos de pesquisa; indicador mais reportado, em cada categoria, em relatórios sustentáveis brasileiros elaborados segundo as diretrizes da GRI; relação entre indicadores de sustentabilidade e simulações de negócios; integrando indicadores de sustentabilidade no jogo de empresas SE E, e considerações finais.

\section{JOGOS DE EMPRESAS COMO FERRAMENTAS DE SIMULAÇÃO INTERESSANTES AO DESEN- VOLVIME NTO DE UMA CON SCIÊ NCIA ORGANI- ZACIONAL SUSTENTÁVEL}

Anderson e Lawton (2009) argumentam que a aplicação de um simulador em um contexto de critérios empresariais é realizada no intuito de se alcançar inúmeros resultados, geralmente segmentados em três categorias principais:

\begin{tabular}{|c|c|c|}
\hline Aprendizagem & Atitudes & Comportamentos \\
\hline $\begin{array}{c}\text { Ensina aos estudan- } \\
\text { tes terminologias, } \\
\text { conceitos e princípios } \\
\text { empresariais gerais, } \\
\text { ou específicos a uma } \\
\text { determinada } \\
\text { disciplina }\end{array}$ & $\begin{array}{l}\text { As atitudes dos } \\
\text { estudantes } \\
\text { direcionam-se } \\
\text { gradativamente } \\
\text { aos aspectos } \\
\text { centrais da } \\
\text { disciplina }\end{array}$ & $\begin{array}{l}\text { Ensina os estudan- } \\
\text { tes a realizarem na } \\
\text { prática a tomada de } \\
\text { decisões por princí- } \\
\text { pios e conceitos } \\
\text { que validem as } \\
\text { escolhas proferidas }\end{array}$ \\
\hline $\begin{array}{l}\text { Auxilia os estudantes } \\
\text { a vivenciarem rela- } \\
\text { ções interdisciplinares } \\
\text { possibilitadas pelas } \\
\text { várias funções depar- } \\
\text { tamentais do jogo } \\
\end{array}$ & $\begin{array}{l}\text { Promove uma } \\
\text { experiência } \\
\text { comum a todos } \\
\text { os alunos da } \\
\text { classe }\end{array}$ & $\begin{array}{l}\text { Incentiva os estu- } \\
\text { dantes a aplicarem } \\
\text { os conceitos apren- } \\
\text { didos em curso }\end{array}$ \\
\hline $\begin{array}{c}\text { D emonstra a } \\
\text { dificuldade de se } \\
\text { aplicar conceitos } \\
\text { organizacionais } \\
\text { aparentemente não } \\
\text { complexos }\end{array}$ & $\begin{array}{l}\text { Instiga os alunos } \\
\text { a se engajarem } \\
\text { nos processos de } \\
\text { aprendizagem }\end{array}$ & $\begin{array}{l}\text { Incrementa a } \\
\text { habilidade de os } \\
\text { estudantes } \\
\text { trabalharem em } \\
\text { grupo }\end{array}$ \\
\hline $\begin{array}{c}\text { Melhora a retenção } \\
\text { de conhecimento } \\
\text { dos participantes }\end{array}$ & & \\
\hline $\begin{array}{c}\text { Incentiva os } \\
\text { estudantes a } \\
\text { transferirem seus } \\
\text { aprendizados para o } \\
\text { mundo dos negócios }\end{array}$ & & \\
\hline
\end{tabular}

Quadro 1: Três categorias de resultados das simulações empresariais

Fonte: Adaptado de Anderson e Lawton, 2009. 
Garson (2009) considera que os temas e tipos de simulações são tão diversos quanto as próprias ciências sociais. De todas as abordagens que tecem o pano de fundo para esses simuladores, quatro são as principais: os modelos em rede, os modelos regionais, os modelos referenciados aos agentes, e os modelos envolvidos por sistemas dinâmicos, caracterizados a seguir.

- Modelos de simulação em rede - Possuem inúmeras aplicabilidades, mas essencialmente assumem praticidade por duas abordagens: pela teoria dos processamentos de dados e modelagem de eventos distintos, e por modelos que envolvem a concepção de estruturas neutras por meio de métodos provenientes do campo social cognitivo e inteligência artificial (BAINBRID GE, 1995; SALLACH, 1988);

- Modelos regionais - Anteriormente utilizados, com exclusividade, em simulações referentes à física ecológica, passam a ser adotados como ferramentas que auxiliam na compreensão dos movimentos interativos entre seres humanos e ecologia. É uma abordagem utilizada para melhor compreender o comportamento humano em escolhas sociais relacionadas a práticas gerenciais orientadas por comportamentos sustentáveis (LATANÉ, LIU, NOWAK, BONEVENTO, ZHENG, 1995);

- Modelos referenciados aos agentes. 0 uso dessa abordagem tem sido estimulado pela riqueza das linguagens operacionais e sistêmicas desenvolvidas para os simuladores que tratam dos comportamentos humanos amparados por essa compreensão. É uma metodologia consistente em termos de avaliação e sofisticação analítica, tanto que geralmente é utilizada em conjunto com as demais abordagens já mencionadas. As simulações, nesse caso, podem partir de uma ambiência simples e alcançar uma aparência de realidade complexa, a qual será amparada por várias regras e normas, instigadas por uma série de articulações entre diversos atores (SAWYER, 2000; STINCHCO MBE, 2001), e

- Modelos envolvidos por sistemas dinâmicos - Tratase de sistemas de equações que podem ser observados como um modelo que aborda uma parcela da realidade. O s modelos envolvidos por sistemas dinâmicos diminuem uma série de indeterminações do meio, pela incorporação dos movimentos cíclicos dos efeitos causais (BARDACH, 2006).

Thavikulwat (2009) admoesta que todos os modelos supramencionados comportam abordagens permissivas de uma discussão sobre fatores de sustentabilidade organizacional na ambiência dos jogos de empresa. A inserção dessa realidade socioambiental em um simulador propõe uma vivência do jogo pela observação dos respectivos aspectos técnicos, por meio de processos de decisões que confluam na solução das problemáticas participadas ao longo das simulações.

Todavia, para a fundamentação prática dessa idealização, de acordo com o mesmo autor, será necessária a concepção de uma abordagem de jogos otimizada em termos estrutu- rais, a fim de que os participantes possam experienciar acontecimentos próximos à realidade, pois, dessa maneira, compreenderão os objetivos do simulador ao perceberem a importância das decisões tomadas como ações possíveis de se estenderem em um cotidiano organizacional.

As práticas de simulações empresariais foram por muito tempo relegadas pelas ciências sociais, mas, em tempos modernos, passaram a ser compreendidas como importantes ferramentas que promovem a compreensão de fenômenos sociais. Por meio das metodologias envoltas aos jogos de empresas, por exemplo, os pesquisadores podem, em relação a um determinado acontecimento social: identificar seus efeitos causais, calcular parâmetros críticos específicos, e, principalmente, evidenciar a importância da simulação como algo pertinente para o entendimento de como os processos se desenvolvem em um espaço de tempo (GARSO N, 2009).

Em síntese, o desenvolvimento de simuladores e a sua aplicabilidade valorizam e enriquecem os processos de escolhas sociais, as quais, segundo Hardin (1968), acontecem por intermédio de uma concomitância interativa entre os seres humanos. Elas divergem das decisões individuais, por serem dependentes de opções alheias. Assim, como a sociedade se torna cada vez mais interconectada, pois os seres humanos condicionam-se, cada vez mais, sobre a existência limitada de recursos naturais comuns, as tomadas de decisões passam a ocorrer por meio de uma relação comunitária e social. Entretanto, inúmeras decisõ es contribuintes a um desenvolvimento harmônico exigem transformações nos valores particulares de cada ser humano, e, também, mudanças nos ideais coletivos de moralidade.

É nessa necessidade de vivenciar mudanças que consiste a principal crítica aos simuladores. De acordo com Abbott (1988), as simulações de todos os tipos, mesmo que alicerçadas em sistemas de equações, ou ainda que fundamentadas pela análise interativa de agentes artificiais, assumem limitações, pois presumem que os atores sociais e as restrições do meio são fixos e imutáveis; logo, mesmo que por uma inconsciência, instigam variáveis comportamentais predeterminadas. Essas variáveis precisam migrar de uma análise determinística e probabilística e alcançar um ambiente de simulação desprovido de regras preestabelecidas, para que, assim, os sujeitos participantes desenvolvam suas potencialidades em plenitude.

A ambiência de um jogo de empresas pode ser, pelo exposto, construtiva para a aquisição de compreensões sustentáveis por parte dos participantes. Ainda que composta por algumas limitações, essa aparência de realidade pode conferir aos sujeitos dessa simulação um melhor entendimento sobre as premissas sociais, ambientais e econômicas envoltas em discussões sobre a sustentabilidade, apresentadas resumidamente em seguida.

\section{CONTEXTUALIZAÇÃO DA ASCENSÃO DE UM NOVO PARADIGMA PAUTADO POR VAL ORES DE SUSTENTABILIDADE SOCIAL E AMBIENTAL}

Em um momento de questionamento sobre as estruturas mundiais, as relações de poder estão ameaçadas, e nelas as elites dominantes enfraquecem-se quanto a seu lugar pri- 
vilegiado nas tomadas de decisões. Logo, uma acepção social mediante as extremas mais valias adquiridas por tais sujeitos sociais faz-se necessária, para que, assim, um consenso comunitário não destitua o poder até então imperante.

Todavia, a ação de tais agentes sociais incorre em consequências ambientais, nem sempre agradáveis. A análise da problemática ambiental se dá por uma diversidade de abordagens, as quais se mostram distintas em alguns pontos e convergentes em outros. Nesse sentido, para uma melhor compreensão, será adotada a via interpretativa das ciências sociais.

Segundo Zioni (2005, p. 39), "para discutir a relação entre as ciências sociais e o meio ambiente, é fundamental uma reflexão sobre o cenário em que essas questões emergiram: a modernidade". Pelo discurso da autora, o ambiente sofreu uma série de alterações, em séculos passados, promotoras de uma sociedade fadada aos dizeres capitalistas, a exemplo das reformas religiosa e social, e das revoluções industriais.

A modernidade trouxe gradativamente uma exigência de sociabilidade do homem para com o meio e vice-versa. O s mecanismos de produção desenvolvidos, se analisados de maneira isolada, pouco emancipam a sociedade atual das comunidades antigas; porém, se aliados aos acontecimentos ambientais, constatar-se-á a emergência de uma nova representação simbólica do mundo por inéditas relações de poder.

Logo, por meio de ocorrências históricas, acontecimentos sociais e desenvolvimentos econômicos, vislumbra-se na modernidade a construção de uma nova representatividade da vida social. Ainda que por formas hegemônicas de conhecimento, a elucidação sobre o movimentar do mundo se dá pela aliança das vertentes sociais e naturais, ao adicionarem em uma dialética recíproca o conhecimento científico e a razão (CO IMBRA, 2002).

É pertinente comentar que ao longo da historicidade econômica não foram promovidas metodologias de desenvolvimento benfeitoras a todas as sociedades e ao meio ambiente. Surgiram inúmeras tentativas explicativas no intuito de justificar algumas atitudes governamentais e até mesmo organizacionais. Todas elas, à sua maneira, contribuíram com algo novo à academia. Mas é concedido um destaque à teoria do desenvolvimento, por seu aprofundamento sociopolítico.

Montibeller (2007, p. 57) admite as teorias do desenvolvimento como "o conjunto de formulações que visa compreender e modificar a realidade pelo exame dos mecanismos segundo os quais os fenômenos sociais inter-relacionamse, dos elementos principais que respondem pela evolução da economia e das tendências seculares".

Representantes e auxiliares fundamentais ao desenvolvimento são as instituições. É imprescindível afirmar que 0 desenvolvimento econômico ocorre em ambientes institucionais por meio de atividades produtivas, negociações virtuais, redes de relacionamento, cadeias de suprimento, além de uma série de estruturas tão possíveis quanto maior for a tecnologia empregada. Percebe-se, por conseguinte, a inerência da atividade inovadora em todos os processos envolvidos.

Nesse contexto, a instituição apresenta-se como protetora da propriedade privada ao incentivar investimentos que apreciem decisões democráticas capazes de disponibilizar socialmente os benefícios oriundos de tais negociações. Montibeller (2007) defende que, para um desenvolvimento adequado, a qualificação institucional é condição necessária, mas insuficiente para sanar os problemas sociais e ambientais em toda a sua contingência.

É fatídico o despreparo do Estado e a ineficiência do setor privado para com as questões ambientais. E ambos são fortes instituições cristalizadas pela legitimação capitalista. Não é correta a crítica unilateral ao sistema, bem como é insatisfatória a plena aceitação dele. Como sinal de emergência, é necessária a reinstitucionalização de muitos modelos, valores, mitos, e de muitas normas, os quais já não atendem a sociedade em sua plena qualidade de vida.

O modelo capitalista é o "representante legítimo e universal da racionalidade, cuja proposta era libertar o homem do reino das necessidades pelo uso científico dos recursos naturais e econômicos do planeta, pela adaptação do conhecimento científico à produção, processos que criariam riquezas incessantemente" (ZIO NI, 2005, p. 41).

Jamais se observou tal nível de inovação e desempenho tecnológico; entretanto, os índices de desenvolvimento humano e de qualidade de vida não acompanham o fator econômico. Tanto é verdade que Montibeller (2007) por sua vernácula admite que, quando em crescimento, a economia instiga degradação, poluição e esgotamento de bens ambientais e, quando da retração das atividades econômicas, as questões ambientais são desprezadas por implicarem custos adicionais.

De acordo com Brunacci e Philip Jr. (2005), a era de conquistar o desenvolvimento econômico sem qualquer restrição e à custa de prejuízos ambientais já não permanece, persistindo, entretanto, em algumas ideologias empresariais. Há de se compreender a insuficiência de fatores naturais, dos quais depende a sobrevivência social do planeta. É ainda mais importante reconhecer que, após a geração presente, outras virão e também habitarão nesse mesmo território.

Segundo Diaz (2002), é iminente a precisão de romper definitivamente com a filosofia do crescimento ilimitado, uma vez que o desenvolvimento insustentável apresentará seu limite de esgotamento em tempo breve, caso as tendências sociais e econômicas não sejam transformadas em prol do bem-estar da população mundial.

Exige-se, portanto, uma nova interpretação sobre o funcionamento econômico no mundo. Mesmo que algumas ações voluntárias venham de empresas e governantes, ainda assim são insatisfatónias, pois é reconhecida a capacidade econômica das nações de apresentarem, conforme Montibeller (2007), um comportamento menos agressivo à natureza somente quando pressionadas por externalidades com poder de regulação.

Entretanto, meio ambiente e economia já se entrelaçam, mesmo que teoricamente. Há uma série de denominações, tais como economia ambiental, economia ecológica, economia humana, em que cada denominação representauma abordagem explicativa do problema. Todavia, o que mais interessa éa dimensão econômica associadaàs questões ambien- 
tais, por ser situação fundamental na formulação de diretrizes de atuação do governo, das empresas e dos cidadãos para a própria compreensão dos fatos e das relações sociais, culturais e políticas (CALDERONI, 2004).

Emerge, então, um novo paradigma, o da sustentabilidade entendido como aquele que

expressa hoje o desejo de quase todas as sociedades, em qualquer parte do mundo, por uma situação em que 0 econômico, o social e 0 ambiental sejam tomados de maneira equânime. Então, não basta apenas haver crescimento econômico, avanço tecnológico e as instituições; e, sim, pensar na revolução tecnológica e no arcabouço institucional objetivando o bem-estar social com a amplitude a este inerente (MO NTIBELLER, 2007, p.59).

Torna-se, então, plausível a ocorrência de um crescimento econômico pautado por características de sustentabilidade; logo, o vocábulo 'sustentável', nas palavras de Brunacci e Philip Jr. (2005, p. 274), ao qualificar o tipo de desenvolvimento que se deseja, "deve ser aplicado à realidade ambiental do presente"

Dentro desse aparato interpretativo, as mudanças institucionais tornam-se necessárias, uma vez que as instituições precisam ser eficientes no atendimento pleno dos anseios originados em diferentes tempos. A iminência de tais transformações faz notória a insustentabilidade do antigo paradigma desenvolvimentista. Por essa evolução da importância da questão ambiental através da economia vislumbram-se as decisões políticas e econômicas sendo alinhadas a preceitos sustentáveis.

Políticas, instituições, tratados ou acordos internacionais que vislumbrem a problemática ambiental pela abordagem sustentável devem ser capazes para transpor as barreiras físicas no intuito de uma maior eficácia na resolução de calamidades. Torna-se cada vez mais imprescindível uma resposta institucional que suponha em seu agir a racionalidade social e econômica do capitalismo permeado no imperativo ambiental.

Essa resposta tem de ocorrer por uma ótica capaz de conjeturar as diferenças e especificidades entre as nações, de maneira que sua intervenção em favor da humanidade e do meio ambiente seja aceita como verdade, e, consequente-mente, como apoio ao acontecimento do desenvolvimento sustentável. O s vieses ambientais não são de responsabilidade exclusiva das nações, das empresas e da humanidade, mas de todos os que habitam no planeta Terra e agem intensivamente sobre ele.

Como afirmou MacNeill e outros autores (1992, p.16), "o mundo avançou agora dainterdependência econômica para a interdependência ecológica - e até, para além desta, para um entrelaçamento entre ambas".

Portanto, de acordo com Zioni (2005), para a solução dos problemas e desequilíbrios evidenciados, propõe-se um novo paradigma de sustentabilidade, que parta da crítica do conhecimento existente, e evolua do monoculturalismo ao multiculturalismo de tal forma que o domínio global da ciência moderna não possa silenciar os outros saberes, e, assim, emancipe-se um conhecimento que consiga discernir a objetividade da neutralidade.
Dentro desse contexto de discussão sobre sustentabilidade, este estudo possui o intuito de apresentar a inserção de indicadores de sustentabilidade nos ambientes de jogos de empresas, para que assim diversos públicos possam interagir com essa realidade envolta por critérios que validam ações sustentáveis das empresas junto à economia, sociedade e ao meio ambiente. Adota-se como padrão de análise o documento internacional proposto pelas 'D iretrizes para Relatório de Sustentabilidade' da Gldbal RepartingInitiative

\section{COMUNICAÇÃO GLOBAL DE AÇÕES SUSTEN- TÁVE IS: GLOBAL REPORTING INITIATIVE}

Conforme a World Comission on Enviranment and Dexdqpment (WCED ), o desenvolvimento sustentável consiste em não comprometer a sobrevivência de gerações futuras, por meio da exploração responsável de recursos naturais no presente (BRUNDTLAND, 1987). Essa concepção agrega em si definições convencionais sobre os objetivos econômicos e sociais da humanidade por uma abordagem de longo prazo, ao considerar questões ambientais em suas premissas.

Em um contexto de articulação entre sociedade, economia e meio ambiente, as organizações passam a sofrer uma série de exigências provenientes de inúmeras fontes de pressões. As empresas, mediante as consequências ambientais geradas pelas suas atividades, precisam alcançar legitimidade social por ações responsáveis que as validem na angariação de recursos, de maneira que possam sobreviver em alicerces estruturados por pressões institucionais coercitivas, normativas e miméticas (FERNANDEZ-ALLES; VALLE CABRERA, 2006).

Entre as iniciativas compostas por princípios de governança referenciados às problemáticas ambientais e exigentes de participações ativas de empresas localizadas ao redor do mundo, constam: o Un'sGldbal Compact, o Organizational for EconomicCoperationandDeudopment's(OECD), as Guiddines for Multinational Enterpises e a Gldbal ReportingInitiative Entre esses movimentos, que se responsabilizam por orientar 0 comportamento sustentável das organizações, destaca-se a Gldbal RepartingInitiative(G RI).

A GRI busca satisfazer a necessidade de uma comunicação clara e transparente, em um âmbito global de compartilhamento de estruturas de conceitos apresentados por uma linguagem coerente, por meio de uma estrutura confiável para a elaboração de relatórios de sustentabilidade, possível de ser utilizada por organizações de todos os tamanhos e setores, e de todas as localidades. A GRI é uma organização independente e global, que conta com a colaboração de especialistas de vários países de todo o mundo, e possui uma estrutura de governança miltistakehdderproveniente de empresas, organizações não-governamentais, trabalhadores, consultores, governos, universidades, institutos de pesquisa e associações empresariais (GRI, 2009). E ssa organização elaborou um documento intitulado "Diretrizes para Relatório de Sustentabilidade". Mais informações sobre a G RI e sobre esse documento são apresentadas em quadro disponível na página seguinte.

Os relatórios de sustentabilidade desenvolvidos pelas empresas (GRI, 2009) precisam conter: 
- Perfil: informações que fornecem o contexto geral para a compreensão do desempenho organizacional, incluindo estratégia, perfil e governança;

- Informações sobre a forma de gestão: dados cujo objetivo é explicitar o contexto no qual deve ser interpretado o desempenho da organização numa área específica;

- Indicadores de desempenho: informações sobre 0 desempenho econômico, ambiental e social da organização passíveis de comparação.

Esses relatórios são classificados em seis níveis diferentes e crescentes: $\mathrm{C}, \mathrm{C}+, \mathrm{B}, \mathrm{B}+, \mathrm{A}, \mathrm{A}+$. Cada letra representa a exigência de critérios específicos, e o símbolo ' + ' indica que houve verificação externa do relatório a ser reportado. Não se discorrerá sobre as diferenças desses relatórios, uma vez que não é esse o objetivo deste estudo.

A GRI indica, ao todo, 79 indicadores, segmentados em essenciais e adicionais. O s indicadores essenciais são aplicáveis e considerados relevantes para a maioria das organizações. Todos os indicadores são dispostos da seguinte maneira (CONJUNTO DE PROTOCOLOS DE INDICADORES: EC, EN, HR, LA, PR, SO, 2009):

- 9 Indicadores de D esempenho E conômico (EC) (7 Essenciais e 2 Adicionais);

- 30 Indicadores de Desempenho em Meio Ambiente (EN) (17 Essenciais e 13 Adicionais);

- 9 Indicadores de Desempenho em Direitos Humanos (HR) (6 Essenciais e 3 Adicionais);

- 14 Indicadores de Desempenho em Práticas Trabalhistas e Trabalho Decente (LA) (13 Essenciais e 1 Adicional);

- 9 Indicadores de Desempenho em Responsabilidade pelo Produto (PR) (4 Essenciais e 5 Adicionais); e

- 8 Indicadores de Desempenho em Sociedade (SO) (8 E ssenciais).

Após a contextualização do tema junto ao referencial teórico desenvolvido e a apresentação da Gldbal Reporting Initiative, apresenta-se, em seguida, o jogo de empresas SEE (Simulador de Estratégia Empresarial).

\section{JOGO DE E MPRESAS SEE (SIMULADOR DE ES- TRATÉGIA EMPRESARIAL)}

O SEE é um jogo de empresas em geral cujo sistema computadonizado foi desenvolvido a partir da concepção estrutural do jogo gerencial. Trata-se de um simulador aplicado em uma universidade pública do sul do País à condução da disciplina 'Jogo de Negócios' em turmas de graduação, pós-graduação e mestrado, em todos os cursos relacionados e vinculados a áreas afins da administração.

O propósito básico desse jogo é simular a gestão estratégica de empresa. Enfatizando as etapas de formulação, implementação e avaliação estratégica, num contexto em que questões relativas a risco e retorno podem ser articuladas de diferentes maneiras para atingir objetivos de longo prazo, 0 SE E busca desenvolver/ ampliar nos participantes a visão estratégica de negócios, a visão competitiva e a visão geral e articulada de empresa. Os indivíduos representam diretorias e vivenciam decisões estratégicas e táticas, típicas das empresas (LO PES, 2001).

A dinâmica do SEE é comum à dos jogos de empresas em geral. O s grupos tomam decisões por instruções angariadas junto ao manual do participante (LOPES, 2009), por notícias divulgadas no jornal do período atual e pelos dados disponibilizados em relatórios confidenciais de resultados de períodos anteriores.

Todas as empresas iniciam a simulação nas mesmas condições. Cada perío do corresponde a um trimestre de vida da empresa. Na rodada inicial, as equipes formulam a estratégia, constituída de um conjunto de objetivos de longo prazo e os principais meios que a empresa irá utilizar para alcançálos. Em cada rodada subsequente, as equipes tomam um conjunto de decisões relacionadas aos diversos processos e às áreas da empresa, como marketing, produção e finanças, implementando a estratégia e buscando conduzir a empresa aos objetivos.

Uma vez discutidas e acertadas, as decisões são encaminhadas por meio de formulários impressos, disquetes ou ainda via rede de computadores, conforme os recursos disponíveis. Recebidas, as decisões das equipes são processadas pelo SEE e o relatório confidencial de resultados é devolvido. As informações desse relatório permitem que cada equipe analise e projete suas diretrizes futuras de gestão. As empresas também contam com o suporte do jornal SE ENEWS, que traz informações sobre variações conjunturais do ambiente e eventuais variações de preços.

O jogo é finalizado por uma assembleia de acionistas, ocasião em que as empresas apresentam os objetivos estratégicos inicialmente traçados, a estratégia seguida e os resultados alcançados. 0 encerramento efetivo se dá como uma avaliação qualitativa conduzida pelo professor, com a identificação de conceitos relevantes presentes no processo de simulação desenvolvido e que se constituem nos objetivos pedagógicos da atividade.

\section{METOdol OGIA E PROCEDIMENTOS DE PES- QUISA}

Conforme teorização metodológica proposta por Martins e Teóphilo (2007), este trabalho desenvolve-se como uma pesquisa de natureza básica. A abordagem do problema aconteceu de maneira qualitativa. Os objetivos foram analisados do ponto de vista descritivo. Classificou-se os procedimentos técnicos como bibliográfico e documental. Foi elaborado um levantamento teórico-metodológico sobre jogos de empresas e sustentabilidade. Também foi introduzida a Gldbal Reporting Initiativecomo promotora de um padrão de comunicação global em ações empresariais sustentáveis. Finalmente, apresentou-se o jogo de empresas SEE (Simulador de E stratégia Empresarial).

$\mathrm{O}$ artigo objetivou propor a inserção de indicadores de sustentabilidade em ambientes de simulações de negócios. Para tanto, houve uma preocupação de apresentar indicadores diretamente vinculados às realidades das empresas brasi- 
leiras. Assim, foram analisados todos os relatórios de sustentabilidade das empresas brasileiras publicados no ano de 2008 que estiveram em conformidade com as diretrizes da Gldbal RepartingInitiative

O levantamento das empresas brasileiras que publicaram relatórios de sustentabilidade de acordo com as diretrizes da GRI, bem como a aquisição desses documentos, que foram possibilitados pelo site CorparateRejister.com(acessos realizados em 14 de maio de 2009). Trata-se de um serviço gratuito orientado a apresentar ações e relatórios empresariais de sustentabilidade, segundo critérios da GRI, AA 1000A S, e do Gldbal Compact.

D e acordo com a CorparateRegister.com 53 empresas brasileiras publicaram relatórios de sustentabilidade, nas diretrizes estabelecidas pela GRI em 2008. Desse total, 2 não puderam ser incluídas na análise por não apresentarem o relatório completo junto ao site pesquisado até a data de coleta de dados para o presente estudo (14 de maio de 2009). Assim, 51 relatórios de empresas brasileiras que publicaram esses documentos nas diretrizes estabelecidas pela G RI, em 2008, foram analisados.

Esses relatórios são constituídos por indicadores segmentados nas seguintes categorias: econômica, meio ambiente, direitos humanos, práticas trabalhistas, responsabilidade sobre 0 produto e sociedade. Todos os relatórios das empresas adotadas como amostra de pesquisa foram analisados, e de cada relatório foram coletados todos os indicadores reportados no ano de 2008.

Sendo assim, por meio dessa análise documental e desse levantamento de informações, houve um interesse de identificar qual o indicador mais reportado, em cada categoria supramencionada, pelas empresas brasileiras que publicaram relatórios de sustentabilidade conforme as diretrizes da GRI em 2008.

Foram, consequentemente, verificados os seis indicadores com maior índice de presença junto aos relatórios das empresas brasileiras no ano referido, de acordo com as categorias mencionadas. Propõe-se a inserção desses indicadores em simulações de negócios, por constarem em grande parte dos relatórios de sustentabilidade brasileiros.

Para tanto, foi desenvolvida uma breve análise de integração desses seis indicadores de sustentabilidade mais reportados em 2008, junto ao jogo de empresas SE E. Ressalta-se que, embora disponibilizados ao público em 2008, os documentos analisados são constituídos por indicadores alcançados durante o exercício das respectivas empresas no ano de 2007.

7 INDICADOR MAIS REPORTADO, EM CADA CATEGORIA, EM RELAT ÓRIOS SUSTENTÁVE IS BRASIL EIROS E LABORADOS SE GUNDO AS DIRE TRIZES DA GRI

D entro de cada categoria, realizou-se um levantamento quantitativo interessado em verificar qual o indicador mais frequentemente reportado pelas empresas brasileiras em 2008. O s indicadores são identificados a seguir:
- Frequência dos indicadores econômicos: 0 indicador de desempenho econômico mais reportado pelas empresas brasileiras em 2008 foi o EC1 (presente em 46 relatórios), que indica o "valor econômico direto gerado e distribuído, incluindo receitas, custos operacionais, remuneração de empregados, doações e outros investimentos na comunidade, lucros acumulados e pagamentos para provedores de capital e governos" (Conjunto de Protocolos de Indicadores: EC, 2009, p. 4).

- Frequência dos indicadores do meio ambiente: 0 indicador de desempenho em meio ambiente mais reportado pelas empresas brasileiras em 2008 foi o EN3 (presente em 44 relatórios), que se refere ao "consumo de energia direta discriminado por fonte de energia primária" (Conjunto de Protocolos de Indicadores: EN, 2009, p. 8).

- Frequência dos indicadores de direitos humanos: 0 indicador de desempenho em direitos humanos mais reportado pelas empresas brasileiras em 2008 foi 0 HR6 (presente em 40 relatórios), que apresenta as "operações identificadas como de risco significativo de ocorrência de trabalho infantil e as medidas tomadas para contribuir para a abolição do trabalho infantil" (Conjunto de Protocolos de Indicadores: HR, 2009, p. 9).

- Frequência dos indicadores de práticas trabalhistas: 0 indicador de desempenho em práticas trabalhistas mais reportado pelas empresas brasileiras em 2008 foi o LA1 (presente em 51 relatórios), que indica "0 total de trabalhadores por tipo de emprego, contrato de trabalho e região" (Conjunto de Protocolos de Indicadores: LA, 2009, p. 5).

- Frequência dos indicadores de responsabilidade sobre 0 produto: 0 indicador de desempenho em responsabilidade sobre o produto mais reportado pelas empresas brasileiras em 2008 foi o PR5 (presente em 39 relatórios), que engloba as "práticas relacionadas à satisfação do cliente, incluindo resultados de pesquisas que medem essa satisfação" (Conjunto de Protocolos de Indicadores: PR, 2009, p. 8).

- Frequência dos indicadores de sociedade: 0 indicador de desempenho em sociedade mais reportado pelas empresas brasileiras em 2008 foi o SO 1 (presente em 40 relatórios), que apresenta a "natureza, escopo e eficácia de quaisquer programas e práticas para avaliar e gerir os impactos das operações nas comunidades, incluindo a entrada, operação e saída" (Conjunto de Protocolos de Indicadores: SO, 2009, p. 3).

\section{RELAÇÃO ENTRE INDICADORES DE SUSTEN- TABILIDADE E SIMULAÇÕES DE NEGÓCIOS}

O que mais instigou a proposição deste artigo foi a possibilidade de propor a inserção de indicadores de sustentabilidade em uma ambiência de simulações de negócios. Por essa aplicação sistemática e contínua, observa-se a possibili- 
dade da geração de conhecimentos, habilidades e atitudes inerentes a uma realidade estruturada por premissas de sustentabilidade. Para tanto, esse processo de aprendizagem precisa ocorrer por uma abordagem holística, de maneira que, pela elaboração de um cenário que envolva acontecimentos organizacionais, governamentais, sociais e ambientais, o indivíduo tenha seus processos cognitivos estimulados.

De acordo com Anderson e Lawton (2009), alterações dos padrões de comportamentos apenas ocorrem mediante a participação dos indivíduos em simulações que exijam ações repetitivas para o controle ou a resolução de um fenômeno social. Essa situação promove a transferência dos conhecimentos adquiridos para as ocorrências organizacionais cotidianas. Porém, a angariação, interpretação e transferência de novos conhecimentos apenas são possibilitadas pela compreensão cognitiva dos procedimentos envoltos a uma problemática vivenciada.

Essa capacidade de cognição gera uma série de adaptações de conhecimentos adquiridos em diversas situações diferentes, para que, assim, eles sejam utilizados na resolução de problemas específicos. Ainda segundo Anderson e Lawton (2009), caso os processos de desenvolvimento da compreensão cognitiva sejam falhos, ocorrerá uma inibição de atitudes orientadas a transformações; logo, não serão verificadas ações coerentes e apropriadas para um cenário exigente de mudanças.

As simulações, de acordo com Bloom, Englehart, Furst e Krathwohl, todos citados pelos autores mencionados acima, permitem que o indivíduo alcance um domínio cognitivo sobre as situações propostas em uma ambiência de jogos de empresas. Eles propõem que a aprendizagem coletada desses procedimentos acontece em seis fases consecutivas, demonstradas a seguir.
Percebe-se que o indivíduo, em um primeiro contato com a temática oferecida por um jogo, nada possui além de seus conhecimentos básicos. Todavia, ao fim de todas as simulações participadas, já conquista um nível maior de compreensão sobre os critérios possivelmente inseridos em um contexto organizacional, estruturado por uma realidade próxima à proposta pelas simulações de negócios. Vale ressaltar que o desenvolvimento de cada um depende, em grande parte, do potencial cognitivo particular. Mas cabe àquele que desenvolverá o sistema a concepção de um ambiente igualitário em termos de potencialidades de evolução de conhecimentos.

Jarmon, Keating e Toprac (2008) consideram que a efetividade teórica e prática de um sistema de simulações alcança sua plenitude por meio das seguintes preocupações atendidas:

- Preparação do público para os efeitos sociais do fenômeno a ser trabalhado;

- Compreensão das possíveis perspectivas múltiplas geradas;

- Visão geral e sintética de um cenário envolto por premissas diretamente relacionadas ao fenômeno a ser simulado, e

- Incentivo a procedimentos que exijam interligações teóricas, realizações de pesquisas, e validação de possíveis aplicações.

Admoesta-se que os indivíduos precisam sentir uma dose de realidade junto às simulações vivenciadas, para estimularem suas respectivas capacidades cognitivas. Este artigo se preocupou com essa prerrogativa. Tanto que a proposição

Tabela 1: D omínio cognitivo: a taxonomia e os objetivos de aprendizagem de Bloom

\begin{tabular}{lll}
\hline Objetivos de aprendizagem & \multicolumn{1}{c}{ Descrição da aprendizagem } & \multicolumn{1}{c}{ Processos de avaliações } \\
\hline Conhecimento básico & O aluno relembra ou reconhece informações & Respostas a questionamentos diretos \\
\hline Compreensão & $\begin{array}{l}\text { O aluno transforma a informação em uma for- } \\
\text { ma simbólica de compreensão particular }\end{array}$ & $\begin{array}{l}\text { Habilidade de agir sobre ou processar infor- } \\
\text { mações por meio de reformulações proferi- } \\
\text { das em termos particulares }\end{array}$ \\
\hline Aplicação & $\begin{array}{l}\text { O aluno descobre relações, generalizações e } \\
\text { habilidades }\end{array}$ & $\begin{array}{l}\text { Aplicação de conhecimento na resolução de } \\
\text { problemas simulados }\end{array}$ \\
\hline Análises & $\begin{array}{l}\text { O aluno resolve problemas por meio de conhe- } \\
\text { cimentos conscientes sobre relacionamentos } \\
\text { observados entre componentes e princípios } \\
\text { organizadores de um determinado sistema }\end{array}$ & $\begin{array}{l}\text { Identificação de assunções críticas, alternativas } \\
\text { e restrições de uma situação problemática }\end{array}$ \\
\hline Síntese & $\begin{array}{l}\text { O aluno vai além do que já é conhecido e pro- } \\
\text { move novas contribuições }\end{array}$ & $\begin{array}{l}\text { Soluções de problemas que requerem } \\
\text { proposições originais e criativas }\end{array}$ \\
\hline Avaliações & $\begin{array}{l}\text { O aluno desenvolve a habilidade de criar pa- } \\
\text { drões de julgamento, ponderações e análises }\end{array}$ & Consistências lógicas e atenção a detalhes \\
\hline
\end{tabular}

Fonte: Bloom, Englehart, Furst, Krathwohl apud ANDERSON, LAWTO N, 2009, p.199. 
de indicadores de sustentabilidade em um sistema de simulações não aconteceu de maneira aleatória. Houve um interesse de identificar quais os indicadores mais reportados pelas empresas brasileiras. Foram analisados, por isso, 51 relatórios de sustentabilidade publicados em conformidade com as diretrizes da Gldbal RepartingInitiativeno ano de 2008.

O sindicadores mais reportados foram: EC1, EN3, HR6, LA1, PR5, e S0 1, todos previamente apresentados. A proposição de seis indicadores de sustentabilidade se relaciona com as simulações de negócios, por gerar uma interligação de discussões orientadas por categorias econômicas, ambientais, trabalhistas, produtivas e sociais. Essa articulação instiga uma comunicação mais transparente entre os departamentos da empresa simulada, de maneira que todos os participantes são convidados a proferir suas opiniões e conhecimentos à resolução de problemáticas que venham a confluir em decisões vinculadas a uma realidade sustentável.

Além de prover os indivíduos com um maior domínio sobre os temas selecionados, um jogo constituído por indicadores de sustentabilidade pode promover simulações de interações não somente internas, mas principalmente externas. 0 relacionamento com os fornecedores, a satisfação dos consumidores, a flexibilidade governamental, a carga dos tributos, a qualidade da mão de obra, o bom diálogo com os sindicatos e a preocupação com os fatores socioambientais, aglomeram-se e exigem da empresa um posicionamento sustentável para com toda a sua cadeia de relacionamento, a qual transcende os limites internos de uma organização.

Essas ações somente serão validadas se os stakehddars possuírem um conhecimento coerente para com as realidades possíveis de ser enfrentadas pelas organizações. Daí a proposição imprescindível de indicadores de sustentabilidade em uma ambiência de simulações de negócios.

\section{INTEGRANDO OS INDICADORES DE SUSTEN - TABILIDADE NO JOGO DE EMPRE SAS SEE}

Considerando-se que os jogos de empresas gerais configuram uma ambiência adequada para construir conhecimento e atitudes alinhadas ao paradigma da sustentabilidade, foi identificado o jogo de empresas SEE como base viável para a proposta de inserção dos indicadores selecionados. Essa opção justificou-se porque o referido jogo já possui um módulo que integra uma avaliação e reflexão relativa à ética empresarial, e que oferece um conjunto de decisões sobre dilemas éticos, cujos impactos em resultados econômicos, ambientais e sociais são objetivamente estabelecidos. Assim, buscou-se estabelecer e apresentar as relações de correspondência e adaptações necessárias, tanto no algoritmo do simulador como na dinâmica do jogo, para cada um dos indicadores.

Na medida em que os indicadores incorporam elementos de diferentes naturezas, incluindo aspectos econômicos, ambientais e sociais, a proposta pode caracterizar-se como um sistema próprio de avaliação de resultados das equipes no jogo de empresas ou como um sistema complementar ao sistema de avaliação original. Entretanto, para o escopo deste estudo o objetivo é apresentar como cada indicador estará representado no jogo e como integrará sua dinâmica.

O Quadro 02 apresenta os indicadores de sustentabilidade selecionados e a correspondente representação no jogo de empresas SEE.

Considera-se que tais adaptaçõ es são viáveis e assimiláveis pela estrutura e pelo algoritmo do jogo SEE. Considerase também que os indicadores de sustentabilidade gerados pela dinâmica do jogo poderão expressar adequadamente as distinções das decisões tomadas pelas equipes/ empresas e a maior ou menor aderência ao paradigma da sustentabilidade. Finalmente, a diversidade representada pelos indicadores revela uma ampla representação da natureza sustentável da gestão, que poderá, no conjunto, ser utilizada como ferramenta avaliativa do desempenho.

\section{CONSIDERAÇÕES FINAIS}

O artigo foi desenvolvido com o objetivo de propor a inserção de indicadores de sustentabilidade em ambiências de simulações de negócios. Para tanto, foi elaborado um levantamento teórico-metodológico sobre jogos de empresas e sustentabilidade, foi introduzida a Gldbal Reparting Initiative como promotora de um padrão de comunicação global em ações empresariais sustentáveis, e por fim apresentou-se 0 jogo de empresas SEE (Simulador de Estratégia Empresarial). Em seguida foi identificado o indicador mais reportado, em cada categoria, pelos relatórios sustentáveis brasileiros em conformidade com as diretrizes da GRI, e realizadas duas análises: a primeira, sobre a relação entre os indicadores de sustentabilidade e as simulações de negócios, e, a segunda, sobre a integração desses indicadores de sustentabilidade no jogo de empresas SEE.

Em um contexto exigente de critérios socialmente responsáveis, as empresas precisam legitimar-se junto à sociedade como atores praticantes de operações sustentáveis. A informação desse comportamento ao meio ocorre por inúmeros documentos, entre eles os relatórios de sustentabilidade, cujo modelo padrão adotado para este estudo foi o defendido pela Gldbal Reparting Initiative Esse relatório é constituído por indicadores de economia, meio ambiente, direitos humanos, práticas trabalhistas, responsabilidades sobre o produto e sociedade.

No ano de 2008 foram publicados 53 relatórios sustentáveis em conformidade com a GRI, dos quais 51 foram passíveis de análises. Todos esses documentos foram analisados e deles extraído o indicador mais reportado em cada categoria supramencionada. Esses indicadores de sustentabilidade EC1, EN3, HR6, LA1, PR5, e SO 1 - são coerentes para com a realidade organizacional brasileira por estar presentes na maioria dos relatórios sustentáveis. Em relação ao Simulador de Estratégia Empresarial (SEE), todos os indicadores apresentam aplicabilidade plausível, com exceção do EN3, para o qual deverá ser criada uma relação entre o consumo de energia e a capacidade da planta produtiva ajustada pela ociosidade. 


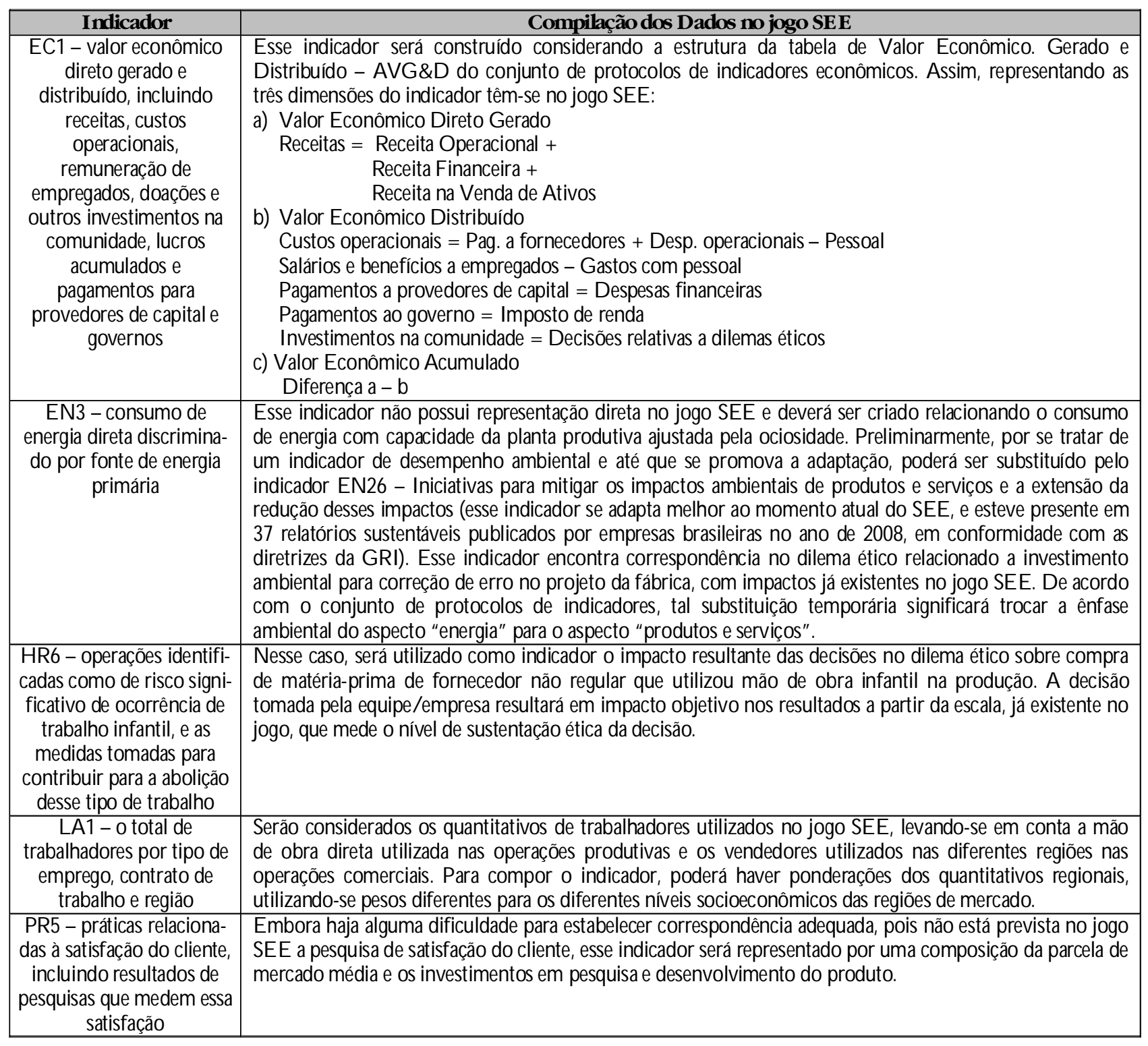

Quadro 2: Os indicadores de sustentabilidade selecionados e a correspondente representação no jogo de empresas SEE

Fonte: Elaborado pelos autores.

É necessário ressaltar que o pleno desenvolvimento dos conhecimentos possíveis de serem angariados em simulações envolvidas por essa temática é dependente do cenário construído ao redor do jogo, e, principalmente do engajamento e comprometimento dos participantes.

\section{RE FE RÊ NCIAS}

ABBOTT, A. Transcending general linear reality. Sododogcal theory. v. 6, n. 2, 1988, p. 169-186.

AND ERSON, Philip H.; LAWTON, Leigh. Business simulations and cognitive learning: developments, desires, and future directions. Simlation \& Gaming v. 40, n. 2, p. 193-216, april 2009.

BAINBRID GE, W.S. Neural network models of religious belief. Socidogical pespeetives v. 38, n. 4, p. 483-195, 1995.
BARDACH, E. Policy dinamics. In: M. Moran, M. Rein; R. E. Goodin (Eds.). The Oxford handbodk of public policy. New York: Oxford University Press, 2006, p. 343-366.

BRUNACCI, Attilio; PHILIP Jr., Arlindo. Dimensão Humana do D esenvolvimento Sustentável. In: PHILIP Jr, Arlindo; PELICIO NI, Maria Cecília Focesi. Educação ambiental e sustentabilidade Barueri: Manole, 2005, p. 257-283.

BRUNDTLAND, G. H. Our common future, World Commission on Enviramment andDerdopment. The first edition, O xford: O xford, 1987. CALD ERONI, Sabetai. Economia Ambiental. In: PHILIP Jr, Arlindo; ROMÉRO, Marcelo A.; BRUNA, Gilda C. Curso de gestão ambiental. Barueri: Manole, 2004, p. 571-617.

COIMBRA J. A. O atroladodb mio andiente Campinas: Millenium, 2002. 
Conjuntodeprotocolosdeindicadores econômico; meio ambiente; responsabilidade sobre o produto; práticas trabalhistas; direitos humanos; e, sociedade. D isponivel em: <http:/ / www.globalreporting.org/ Home / LanguageBar/ PortugueseLanguagePage. htm > . Acesso em: 16 mar. 2009.

DIAZ, A. P. A educacãoambiental compprojeo 2 ed., Trad. de F. Murad. Porto Alegre: Artmed, 2002.

FERNANDEZ-ALLES, Maria de la luz; VALLE-CABRERA, Ramon. Reconciling institutional theory with organizational theories How neoinstitutionalism resolves ?ve paradoxes. Jaurnal of Organizational ChangeManagement. v. 19, n. 4, p. 503-517, 2006.

GARSO N, G. D avid. Computerized simulation in the social sciences. Simlation \& Gaming v. 40, n. 2, p. 267-279, april 2009.

G3-GRI Dinerizes para relatónios de sustentabilidade Disponível em: <http:/ / www.globalreporting.org/ Home/ LanguageBar/ Portuguese LanguagePage.htm>. Acesso em: 16 mar. 2009.

HARDIN, G. The tragedy of the commons. Saiene 162, 1968, p. 1243-1248.

MacNEIL J.; WINSE MIUS P.; YAKUSHIJI T. Para além da interdependânaia Trad. D e Á. Cabral. Rio de Janeiro: Jorge Zahar, 1992. JARMO N, Leslie; KEATING, Elizabeth; TO PRAC, Paul. Examining the societal impacts of nanotechnology through simulation: NANO SCENARIO. Simulation \& Gaming v. 39, p. 168-181, 2008.

LATANÉ, B.; LIU, J. H.; NOWAK, A.; BONEVENTO, M.; ZHENG, L. D istance matters: physical space and social impact. Personality and social psychologist bulletin v. 21, n. 8, p. 795-805, 1995.

LOPES, P. da C. Manual do Participante do Jogp SEE. Londrina, Universidade Estadual de Londrina, 2009.

MARTINS, G. A.; THEÓ PHILO, C. R. Méoddoga da investicgạão dentífica para dênias sodiais aplicadas São Paulo: Atlas, 2007.

MONTIBELLER F., G ilberto. Empresas desenvdvimento e ambiente diagnóstico e diretrizes de sustentabilidade. Barueri: Manole, 2007. Níveisdeaplicaçãoda GRI. D isponível em: < http:/ / www. globalreporting. org/ Home/ LanguageBar/ PortugueseLanguagePage. htm > . A cesso em: 16 mar. 2009.

Reatónios de Sustentabilidade das 51 empresas addtadas com amostra de pesquisa. D isponível em: <http:/ / www.corporateregister.com/ search/ search.ogi?d=\&n=0\&ret=R\&sec=All\&af=All\&cou=Brazil\&yr=2008\&gri= $1 \& r=g 3 \& g 31=A l l \& g 32=A l l \& n r=30>$. Acesso em: 14 mai. 2009.

SALLACH, D. L. A comparison of parallel architetures: prospective issues in rapid-discovery social science. In: Proceedings of the second ACMsymposiumon artifidal intelligence Norman: O klahoma center for continuing education. 1988, p. 401-417.

SAWYER, R. K. Simulating emergence and downward causation in small groups. In: S. Moss; P. D avidsson (Eds.). Multi-agent-based similation Berlin, Germany: Springer-Verlag, 2000, p. 49-67.

ST INCHOMBE, A. L. When formalityworks authorityandabstration in lawand arganizations Chicago: University of Chicago Press, 2001.

THAVIKULWAT, Precha. Social choice in a computer-assisted simulation. Simulation \& Gaming O nline First, published on May 14, 2009, p. 1-25.

ZIO NI, F. Ciências Sociais e Meio Ambiente. In: PHILIP Jr, Arlindo; PE LICIO NI, Maria Cecilia Focesi. Eduracãoanhiental esustentabilidade Barueri: Manole, 2005, p. 39-58.
Data de Submissão: 12/ 08/ 2009

Data de Aprovação: 28/ 11/ 2010 